\title{
Литологические особенности озерных отложений в долине реки Воронья, Кольский полуостров, Россия
}

\author{
Толстоброва А.Н., Толстобров Д.С., Колька В.В., Вашков А.А., Носова О.Ю. \\ Геологический институт Кольского научного иентра PAH, Anamumbl, tolstobrov@geoksc.apatity.ru
}

Аннотация. В августе 2018 г. в ходе комплексной экспедиции были проведены полевые палеолимнологические исследования в долине реки Воронья Кольского полуострова. Для всех озёр выполнен последовательный отбор кернов на всю мощность донных отложений, проведено литологическое описание и фотографирование седиментационных последовательностей, отобраны пробы для лабораторных анализов. Предварительные результаты исследования позволяют предположить, что в этих озёрах вскрыты отложения морского и современного озёрного происхождения. На основе предварительной интерпретации генезиса донных отложений изученных озер проведена реконструкция положения береговой линии Баренцева моря в долине реки Воронья.

Ключевые слова: озера, донные отложения, литология, долина реки Воронья, Кольский полуостров, голоцен.

\section{Lithological features of lake sediments in the valley of the Voronya river, Kola Peninsula, Russia}

\author{
Tolstobrova A.N., Tolstobrov D.S., Kolka V.V., Vashkov A.A., Nosova O.Yu. \\ Geological Institute, Kola Science Centre, Russian Academy of Sciences, Apatity,tolstobrov@geoksc.apatity.ru
}

Abstract. During the complex expedition in August 2018, field paleolimnological studies were fulfilled in the valley of the Voronya river of the Kola Peninsula. For all lakes, core sampling was carried out for the full thickness of bottom sediments, lithological description and photographing of sedimentation sequences were carried out, and samples were taken for laboratory analyzes. Preliminary results of the study suggest that marine and lacustrine sediments have been identified in these lakes. Based on a preliminary interpretation of the genesis of the bottom sediments of the studied lakes, the position of the Barents Sea coastline in the Voronya river valley has been reconstructed.

Key words: lakes, bottom sediments, lithology, valley of the Voronya river, Kola Peninsula, Holocene.

\section{Введение}

Исследование донных отложений озерных котловин, расположенных на морском побережье, позволяет определить характер перемещения береговой линии моря и оценить амплитуду и скорость поднятия земной поверхности. Такие работы на баренцевоморском побережье Кольского региона были проведены в районах пос. Дальние Зеленцы (Snyder et al., 1997), г. Никель (Corner et al., 1999) и г. Полярный (Corner et al., 2001), в долине р. Тулома (Толстобров и др., 2015; 2016). Но при этом на побережье Кольского региона остается много районов, для которых нет данных об амплитуде и скорости поднятия земной поверхности. Одним из таких районов является долина р. Воронья (рис.1). В данной статье приведены новые данные, полученные в результате полевых работ. На основе предварительной интерпретации генезиса донных отложений изученных озер проведена реконструкция положения береговой линии Баренцева моря.

\section{Район исследования}

Район исследования находится на севере Кольского региона, в районе долины р. Воронья (рис. 1 А), ниже Серебрянской ГЭС-2. Долина реки простирается с юга на север. Относительно краевых образований район исследования располагается в 6 км на восток от внешней полосы пояса II, формирование которого соотносится с похолоданием в древнем дриасе (Система..., 2010). Дневная поверхность района исследования представлена различными гранитоидами архейского возраста (Геологическая..., 1996). Рельеф в районе сильно расчлененный, с небольшими сопками и плато, имеющими абсолютную высоту до 240 м н.у.м. и крутые склоны. В долине реки отмечается ком- 


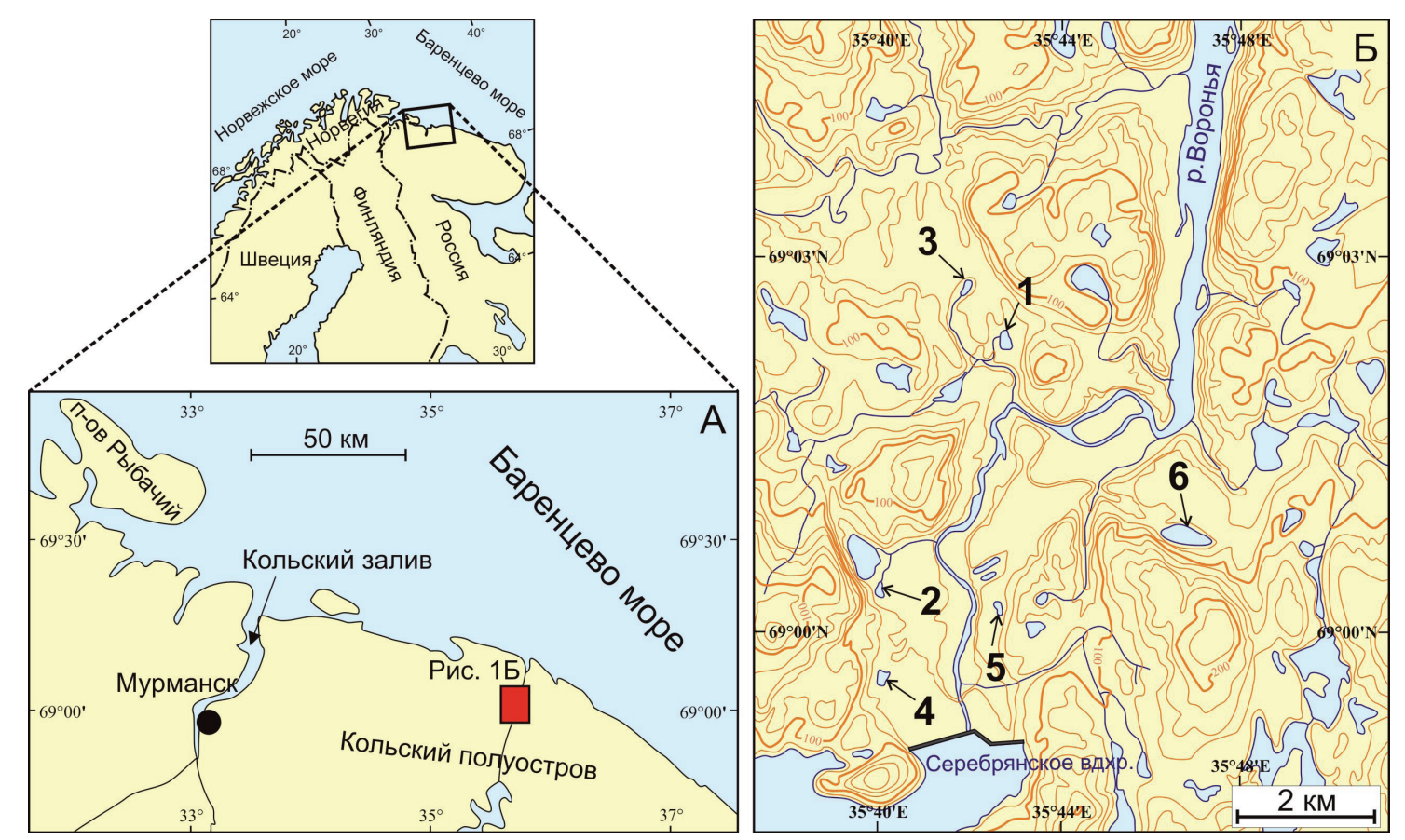

Рис. 1. Положение района исследования (А) и изученных озерных котловин в долине р. Воронья (Б).

Fig. 1. Location of the study area (A) and lake basins in the Voronya River valley (B).

плекс голоценовых морских террас, высота которых достигает примерно 57 м относительно современного уровня моря.

Летом 2018 годы методом изолированных бассейнов (Колька и др., 2013) здесь были изучены донные отложения шести озерных котловин, расположенных на высотных отметках от 23.5 м до 56 м (рис. 1 Б).

\section{Результаты литологического исследования осадков озер и реконструкция положения береговой линии Баренцева моря}

В результате проведенных работ во всех озерных котловинах были вскрыты морские осадки, осадки переходные от морских к пресноводным, современные пресноводные отложения. Морские осадки в разрезе представлены разнозернистым серым песком с единичными зернами гравия, который вверх по разрезу сменяется светло-серым алевритом (в озерах 2-6 на рис. 2). В озерной котловине 1 морские осадки представлены голубовато-серыми глинами с линзами песка (озеро 1 на рис. 2). При поднятии земной поверхности происходило последовательная изоляция озерных котловин от морского бассейна. Во всех котловинах вверх по разрезу отмечается постепенный переход морских осадков к пресноводным. Осадки переходной зоны представлены алевритистой гиттией. После изоляции озера от моря в котловине устанавливался пресноводный режим осадконакопления, происходило формирование озерных осадков представленных гиттией. Для пресноводных отложений озер 1 и 2 был проведен анализ п.п.п. (потери при прокаливании). В результате данные анализа показали низкое содержание органического вещества (10-25 \%) в этих осадках, что указывает на низкую биопродуктивность водоемов и суровые климатические условия в долине р. Воронья.

На основе предварительной интерпретации генезиса осадков изученных озер проведена реконструкция положения береговой линии Баренцева моря. Озеро 6, расположенное на высотной отметке $56 \mathrm{м}$, было изолировано раньше других исследованных озер, предположительнов концепозднего плейстоцена. Вэто время долинареки представляла собой залив моря (рис. 3 А) с глубинами более 60 метров. Море проникало вверх по долине реки на 35 км, до пос. Туманный. Ширина залива достигала более 2 км. Озеро 1, расположенное на высотной отметке 23.5 м, отделилось последним из серии изученных озерных котловин. В разрезе озера 1 отмечается мощная переходная зона (около 70 см). Большая мощность переходной зоны в этом озере указывает на то, что уровень моря долгое время нахо- 

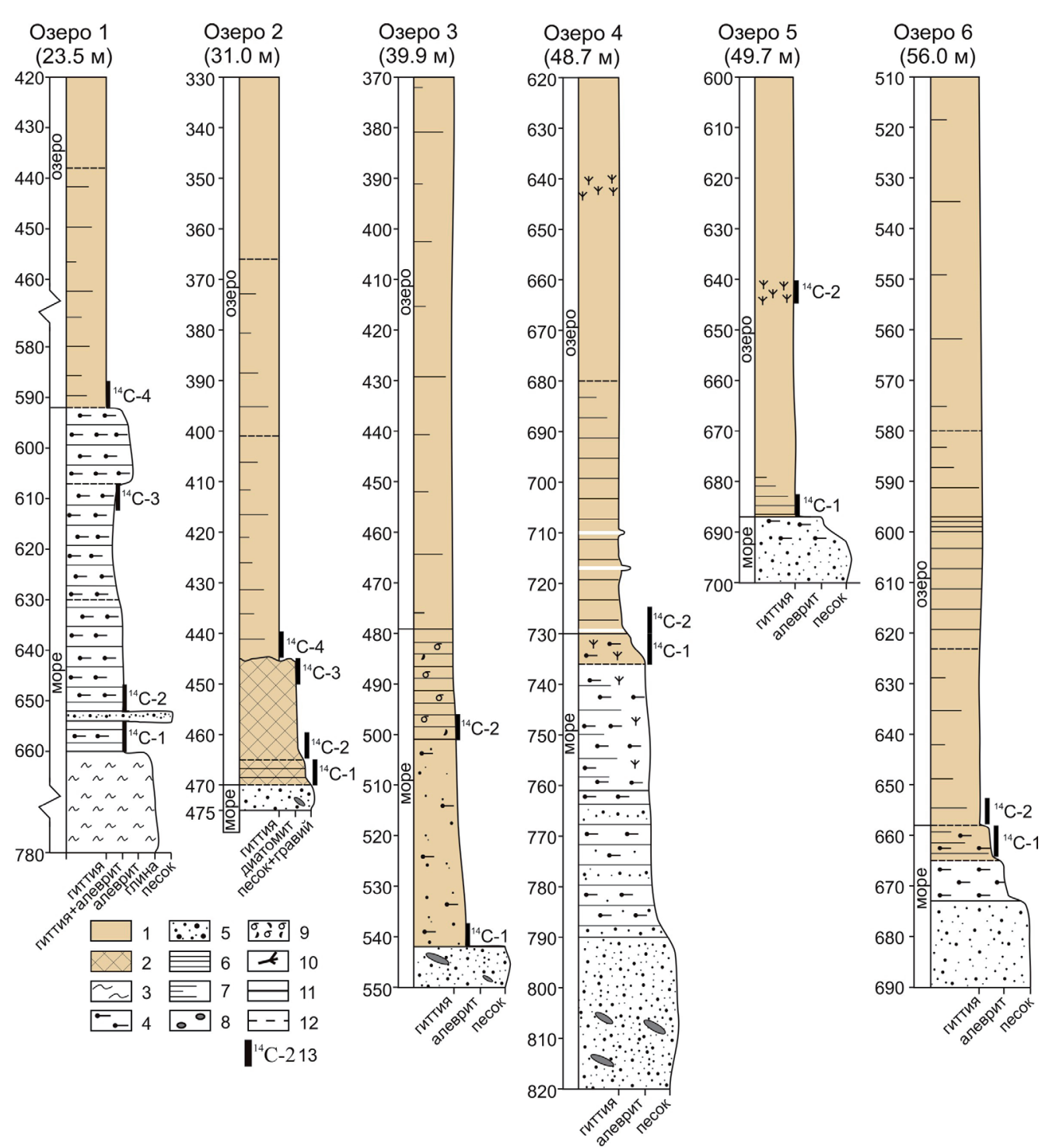

Рис. 2. Разрезы донных осадков озерных котловин, расположенных в долине р. Воронья.

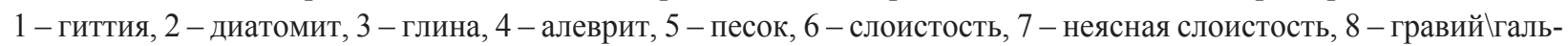
ка, 9 - обломки раковин, 10 - растительные остатки, 11 - резкая граница, 12 - постепенная граница, 13 - интервал на радиоуглеродное датирование.

Fig. 2. Sections of bottom deposits from the lake basins in the Voronya River valley.

1 - gyttja, 2 - diatomaceous, 3 - clay, 4 - silt, 5 - sand, 6 - bedding, 7 - indistinct bedding, 8 - gravel $\backslash$ pebble, 9 - shell fragments, 10 - plant residues, 11 - abrupt boundary, 12 - gradual boundary, 13 - interlayer for the radiocarbon dating.

дился на одной и той же высоте. Возможно, что формирование этих осадков происходило во время морской трансгрессии Тапес. В это время скорость поднятия земной поверхности и скорость эвстатического поднятия уровня моря были примерно одинаковые. Таким образом, зная время проявления трансгрессии Тапес на побережье Баренцева моря, можно предположить, что на высотной отметке около 23 м береговая линия моря в районе исследования находился в среднем голоцене. Площадь распространения морского залива в это время значительно уменьшилась (рис. 3 Б). Морской бассейн в это время проникал на 20 км вглубь континента до места, где в настоящее время расположена Серебрянская ГЭС-2.

\section{Результаты}

В результате в разрезах донных отложений озерных котловин были обнаружены осадки морского происхождения, которые постепенно сменяются современных озерными отложениями (гит- 

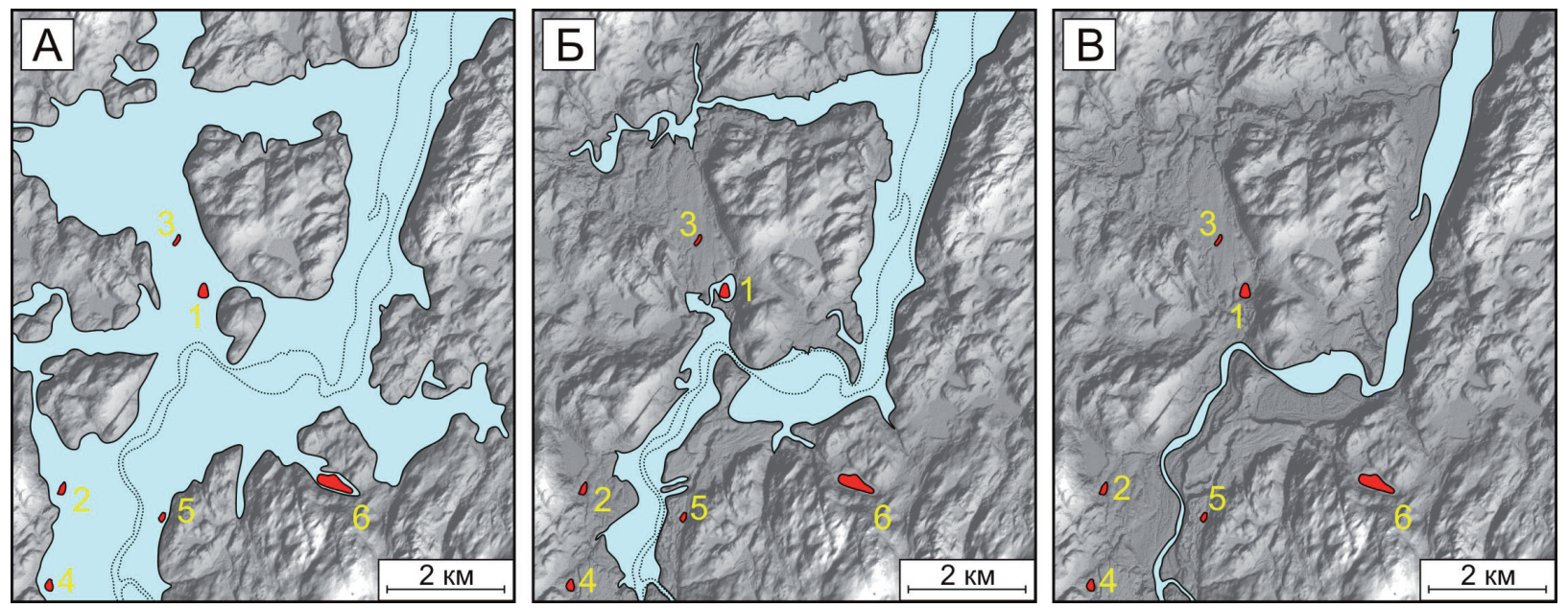

Рис. 3. Реконструкция положения береговой линии Баренцева моря в долине р. Воронья.

Основой является цифровая модель рельефа ArcticDEM. Красным выделены изученные озерные котловины. А - положение береговой линии в конце позднего плейстоцена. Б - положение береговой линии в среднем голоцене. В - современный рельеф.

Fig. 3. Reconstruction of the Barents Sea coastline location in the Voronya River valley.

It is based on the ArcticDEM digital surface model. The studied lake basins are marked in red. A - location of the coastline at the end of the Late Pleistocene. B - location of the coastline in the mid-Holocene. C - modern landscape.

тией). Граница морского бассейна в конце позднего плейстоцена находилась на высотной отметке примерно 60 м. В среднем голоцене береговая линия располагалась на высотной отметке 23 м. В разрезе озерной котловины 1 вскрыты осадки морской трансгрессии Тапес. Результаты последующего диатомового анализа позволят с большей достоверностью охарактеризовать историю развития как отдельных водоёмов, так и всего района исследования. Данные радиоуглеродного датирования помогут выполнить реконструкцию положения береговой линии Баренцева моря во времени.

Авторы выражают благодарность студентам СПбГУ Костроминой Н.А. и Крикуновой А.И. за активное участие в полевых работах.

Работа выполнена в Геологическом институте КНЦ РАН (тема 0226-2019-0054) при частичной поддержке гранта РФФИ №18-35-00054-мол_а.

\section{Литература}

1. Геологическая карта Кольского региона (северо-восточная часть Балтийского щита) масштаба 1:500 000. Гл. ред. Ф.П. Митрофанов. Апатиты. 1996.

2. Колька В.В., Евзеров В.Я., Мёллер Я.Й., Корнер Г.Д. Перемещение уровня моря в позднем плейстоцене - голоцене и стратиграфия донных осадков изолированных озер на южном берегу Кольского полуострова, в районе поселка Умба. Известия Российской академии наук. Серия географическая. М. Изд-во: Наука. 2013. № 1. С. 73-88.

3. Система Белого моря. Т.І. Природная среда водосбора Белого моря. А.П. Лисицын, И.А. Немировская, В.П. Шевченко - ред. М. Изд-во: Научный мир. 2010. 479 с.

4. Толстобров Д.С., Колька В.В., Толстоброва А.Н., Корсакова О.П. Опыт хронологической корреляции береговых форм рельефа голоценового моря в депрессии реки Тулома и Кольском заливе // Вестник МГТУ. 2016. T. 19. № 1/1. C. 142-150.

5. Толстобров Д.С., Толстоброва А.Н., Колька В.В., Корсакова О.П. Постледниковое поднятие земной коры в северо-западной части Кольского региона // Вестник МГТУ. 2015. Т. 18. № 2. С. 295-306.

6. Corner G.D., Yevzerov V. Ya., Kolka V.V., Moller J.J. Isolation basin stratigraphy and Holocene relative sealevel change at the Norwegian-Russian border north of Nikel, northwest Russia // Boreas. 1999. V. 28. № 1. P. 146-166.

7. Corner G.D., Kolka V.V., Yevzerov V.Ya, Moller J.J. Postglacial relative sea-level change and stratigraphy of raised coastal basins on Kola Peninsula, northwest Russia // Global and Planetary Change. 2001. V. 31. P.153-175.

8. Snyder J.A., Forman S.L., Mode W.N., Tarasov G.A. Postglacial relative sea-level history: sediment and diatom records of emerged coastal lakes, north-central Kola Peninsula, Russia // Boreas. 1997. V. 26. P. 329-346. 